\title{
Dissemination of Biomedical Cell Sheets using Reality Technology and Digital Tools
}

\author{
Gwo-Long Lin ${ }^{1}$ \& $\triangle$ and Peng-Hsin Chen ${ }^{2}$ \& \\ ${ }^{7}$ Assistant Professor, Department of Digital Media Design, I-Shou University, Taiwan \\ ${ }^{2}$ Assistant Professor, Center for General Education, National Taichung University of Education, Taiwan \\ $\triangle$ Corresponding Author: Gwo-Long Lin, E-mail: gllin@isu.edu.tw
}

\author{
ARTICLE INFORMATION \\ Received: March 08, 2021 \\ Accepted: April 18, 2021 \\ Volume: 3 \\ Issue: 4 \\ DOI: $10.32996 /$ jhsss.2021.3.4.5
}

\section{KEYWORDS}

Augmented Reality, Virtual Reality, Cell Sheet, 3D Animation, Animation Teaser

\section{ABSTRACT}

Nowadays, with the advance of biomedical and pharmaceutical technology, new treatments such as cell therapy, cell sheets, etc. all provide patients other alternatives. However, the public has little knowledge in these new technologies and they also find them difficult to understand. Hence, this paper is aimed at providing the public with state-of-the-art technological knowledge and constructing an innovative field full of diversity, entertainment, and educational meaning with the assistance of Augmented Reality (AR) and Virtual Reality (VR). Taking the cell sheets technology, a kind of cell therapy recently approved in Taiwan, as an example, we built an AR platform, and demonstrated a trailer animation, 2D animation and 3D model animation via Merge Cube. The trailer animation will portrait how the main character helps her friend, who became physically challenged in an accident, stand up again by asking a genius doctor to perform cell sheet technology. The 2D animation will be used to explain how cell sheet works and its application, while the 3D animation helps demonstrate the DNA reproduction and cell division in cell therapy. A VR field will also be set up so that players can play as the genius doctor, fight their way through the VR games, and learn more about cell sheet technology. To let the public learn more about this biotechnology knowledge, we held an exhibition to display the research results, providing them a whole new learning experience.

\section{Introduction}

As the computing speed of computers continues to advance, Simulation Reality Technologies such as Augmented Reality (AR) and Virtual Reality (VR) have been widely used in multiple fields, including Entertainment, Gaming, Military, Education, Sports...etc. These two types of technologies provide the audience with different experiences respectively. AR can add a cover on real landscapes, such as the game Pokemon Go. It is reported that Pokemon Go has proven how AR games can attract the mainstream population when it initially launched (Palladino, 2018). VR can provide a panoramic view and three-dimensional immersion. With its realization abilities, VR has been commonly used in viewing houses, cars, sports event broadcasting, concerts, or in amusement parks, such as the VR Station in E-Da Theme Park and VIVELAND, the VR Theme Park in Taipei Syntrend Creative Park.

Among all these fields, the Biomedical field should certainly be mentioned. In Taiwan, cancer ranks first in the ten most common death causes, however, the public still has little knowledge on Biomedical Technologies including Glycoscience, Cell Therapy, Precision Medicine, Targeted Therapy, Genetic tests, Next Generation Sequencing, Induced Pluripotent Stem Cells, etc. Questions such as whether Targeted Therapy serves as a cure-all treatment, whether everyone needs to have a Genetic Test, can be difficult for the public to answer if they don't have medical backgrounds. Hence, the main purpose of this research is to introduce Reality Technologies as a teaching tool and help transform heavy Biomedical knowledge into easy-to-understand information.

\section{Literature Review}

Simulation Reality Technologies mainly include $A R, V R$, and Mix Reality (MR), which is the combination of AR and VR. As technology continues to evolve, Simulation Reality Technology has been applied to more and more industries, with multiple

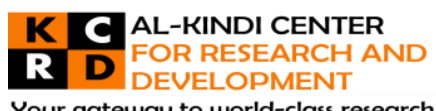

Your gateway to world-class research

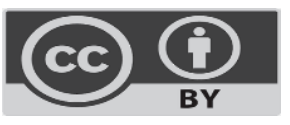

Published by Al-Kindi Center for Research and Development. Copyright (c) the author(s). This open access article is distributed under a Creative Commons Attribution (CC-BY) 4.0 license 
vendors eyeing this business opportunity. It is predicted that Simulation Reality Technology would continue to influence our future in many ways.

AR is a type of technology that can make 3D virtual objects overlap with the real-world landscape, hence the possibilities within AR are endless. Scott Gerber (2013), a young foreign entrepreneur, even views AR as one of the most vital technologies in the future. He gathered the opinions of 13 tech founders and concluded on the Next Web with 13 future technology trends that tech founders could follow while developing their businesses in new fields. AR is listed as one of the trends because it is capable of making virtual scenes on monitors combine with the real world simply by using filming equipment. The article even mentioned that this kind of technology that combines the physical world and digital technology will be the main battlefield in the tech industry and that AR will certainly impact the world extraordinarily just like what the internet did in 1995.

Azuma (1997) proposed three main characteristics AR should have: (1) the ability to combine the virtual and physical world; (2) the capability to interact instantly; (3) the ability to function in a three-dimensional environment. All three characteristics emphasize how AR is closely related to display technology and identification technology especially, which serves as its core technology. AR is a visual amplifying technology. Its display technology should be able to fully project a scene that contains real and virtual objects. This type of technology includes head-mounted, non-head-mounted, transparent panels and holography, etc. Identification Technology, on the other hand, needs to be able to correctly identify real-world objects, and overlap virtual objects onto their spot in the real world. This type of technology includes Specific Tag, Graphical Recognition, Feature Recognition, GPS, or Compass Locating. AR applications can be seen almost everywhere. In 2002, Feiner has brought up multiple possible AR applications in the future (Feiner, 2002), and now, many of the possibilities have become reality. You can play AR games with smartphones in historic sites and cultural and creative parks (Ardito et al., 2007); provide campus or outdoor information via AR in education training sessions (Liarokapis \& de Freitas, 2010; Wang et al., 2011; Mendenhall et al., 2012); apply AR to surgeries (Ha \& Hong, 2016) and anthropotomy (Hackett \& Proctor, 2016) in hospitals.

On the other hand, VR integrates three kinds of technology with multiple sensors and a three-dimensional environment in order to let users immerse themselves in the virtual world. The three technologies include a head-mounted display with a tracking system, an earphone set that provides sound, music, filters noises, and a navigation operating device (Li et al., 2011). The headmounted display shows the users a three-dimensional image and uses motion tracking sensors to decide the location. At the same time, users can control the device and interact with objects they see while hearing the sound effects in the earphones, which makes them feel like they are virtually there and moving around (Malloy \& Milling, 2010). Due to these characteristics, in the past 10 years, VR application has extended from the Entertainment Industry to Clinical Medicine. Researchers and doctors cooperated to examine the simulation effect of $V R$, and it has now been applied to physiotherapy, pain management, surgical training, anthropotomy education, and treatments for psychiatric disorders (Li et al., 2011; Baldominos et al., 2015; Alaker, Wynn \& Arulampalam, 2016; Hackett \& Proctor, 2016; Li et al., 2017).

\section{Methodology}

This project is the result of cross-field cooperation. Since the public finds it difficult to understand Biomedical knowledge, we decided that it would be best to coordinate with teams from other fields to properly demonstrate this topic with Reality Technology. Hence, here is our team and how the three units have coordinated throughout the process:

- Department of Biological Science and Technology, I-Shou University interpreted biomedical frontier technology news into popular science material.

- Our department (Department of Digital Media Design, I-Shou University) combined the provided popular science materials with innovative education technology and developed an amusing and innovative popular science resource module.

- Institute of Education, National Yang Ming Chiao Tung University is responsible for research assessment and will hold an examination for partner schools on the cognitive side, affective side, and skill side.

This research is about the Dissemination of Cell Sheet Applied with Reality Technology. Cell Sheet is one of the cell therapy approved by the "Regulations Governing the Application or Use of Specific Medical Techniques or Examinations, or Medical Devices" (also referred to as the "Regulations of Special Medical Techniques"). It is mainly used in Regenerative Medicine, and it works by making the human cell regenerate functional organ cells to help repair damaged organs. Japanese scientist Shinya Yamanaka discovered iPS (induced Pluripotent Stem) Cell and received the Nobel Prize in 2012, which prompted Japan to invest large amounts of funds in developing cell medical technology. Currently, in Japan, doctors use patients' thigh cells to treat their heart disease, and this method is mostly used in cases of heart failure (Formosa TV, 2017). The Japanese medical team revealed that one of the greatest advantages of using cell sheet surgery is that there will be no side effects for patients, unlike other medicines or chemotherapy. This discovery sets a milestone for Regenerative Medicine and makes a great impact on the public's 
health. Hence, this research is expected to help disseminate the importance of cell sheet application in damaged knee joint cartilage transplant with AR/VR.

This year, for AR application, we continued to use the AR technology we have used in the research case last year, which is the Merge Cube, to help disseminate the importance of cell sheets. The basic system framework of the Dissemination of Cell Sheets via $A R$ we completed this year is shown below, including trailer animation, cell sheet animation, glycoscience courses, 3D animation, volume settings, team members, etc.

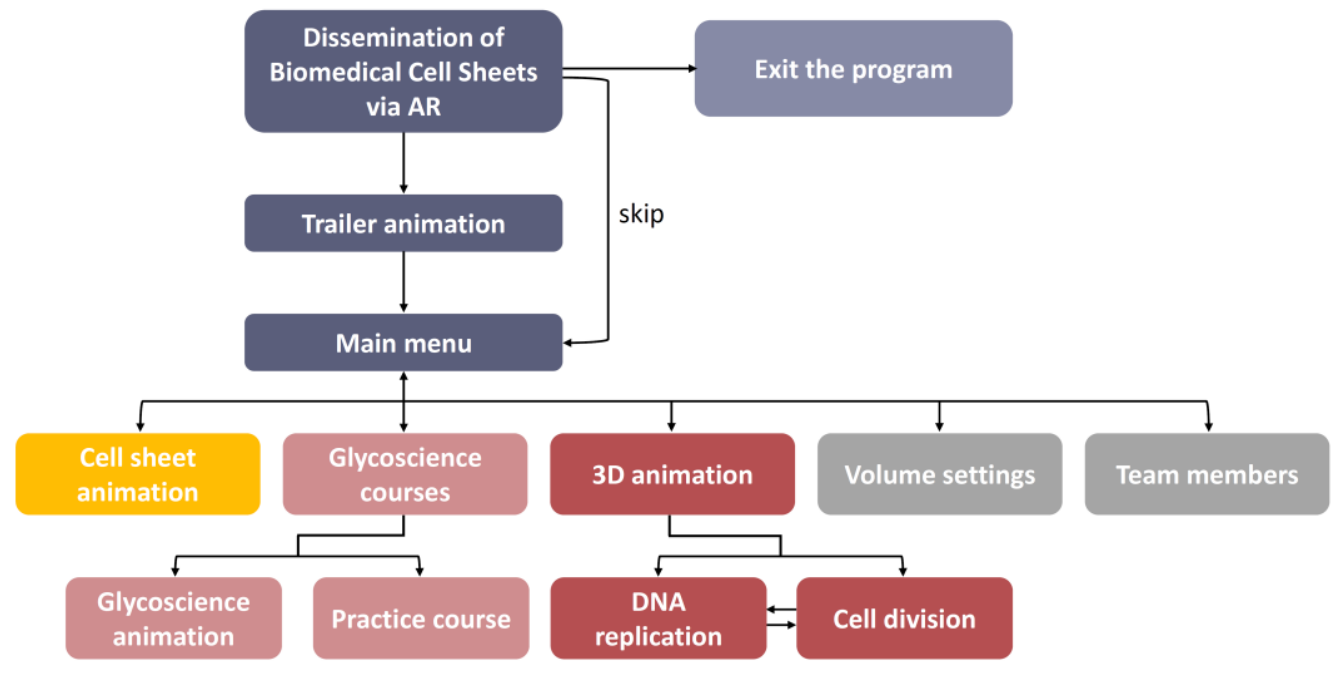

Figure 1: Basic System Framework of the Dissemination of Cell Sheets via AR

For VR applications, we developed the Dissemination of Cell Sheets via VR, using the most immersive VR head-mounted device in the market, HTC VIVE Pro, to immerse themselves in the environment learning how cell sheets work at the same time. The basic system framework of the Dissemination of Cell Sheets via VR is shown below. Once users entered the VR game, they will see two options in the main menu: Review Cell Sheets Animation and Start VR game. The former provides users with a chance to review cell sheets knowledge so they can pass the VR game more easily; the latter lets users experience the VR game by collecting cells in the first level and then go through other levels such as Artificial Joint Model and Cell Sheet Model etc., in order to disseminate biomedical knowledge in cell sheets.

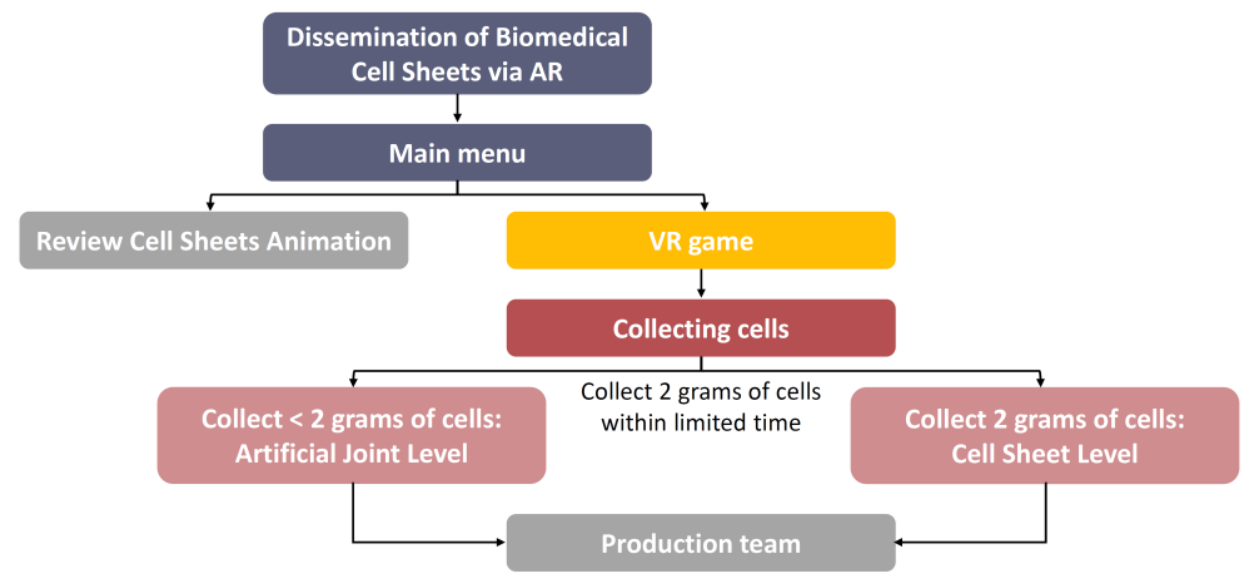

Figure 2: Basic System Framework of the Dissemination of Cell Sheets via VR

\section{Results and Discussion}

To let the public learn about cell sheets more easily, we adopted one key factor of Design Thinking that Tim Brown, the field's master, has mentioned: To write a script that says the most intriguing story. Hence, the story is set at the time when Lily came back from Magic School, but found out her best friend, Ho, got into a car accident. Ho's knee joint got damaged so badly that he wasn't able to exercise anymore. Seeing this situation, Lily went to seek the help of the Dean's friend, who was known as the 
"Genius Doctor" because he is great at performing surgeries that other doctors never dared to perform. The Genius Doctor helped Ho by performing a joint surgery using Cell Sheets in Regenerative Medicine and completed a cartilage transplant for his knee joint, helping him realize his dream of being back in the sports court. After the users view the trailer to understand the plot, they can then watch the 2D animation that introduces how cell sheets are used in the knee joint cartilage transplant. Finally, they can learn about the principles of cell sheets by showing cell replication and cell division with 3D animation. The results are displayed with AR interactive platform so the users can operate it by themselves. Besides, there will also be an advocacy film in cell sheets using VR, in which users can play a part in the script by playing VR games and learning knowledge about cell sheets at the same time.

The software we use to develop this project includes Adobe Photoshop, Illustrator, Maya, Unity, Vuforia, etc. The software is used to build character models, scenes, animation, AR interaction, VR games, etc. For AR technology, we continued to use Merge Cube with smartphones to build the AR learning environment for the dissemination of cell sheets. As for VR, we Used HTC VIVE Pro with controllers so users can experience the VR learning environment for cell sheets advocacy.

The results are summarized as below:

\subsection{Trailer Animation}

According to the plot, other than the main characters, Lily and Carby, in last year's research case, new characters, including Lily's friend Ho, Genius Doctor, etc. are also added. The character models and the screenshot of the trailer are shown below:

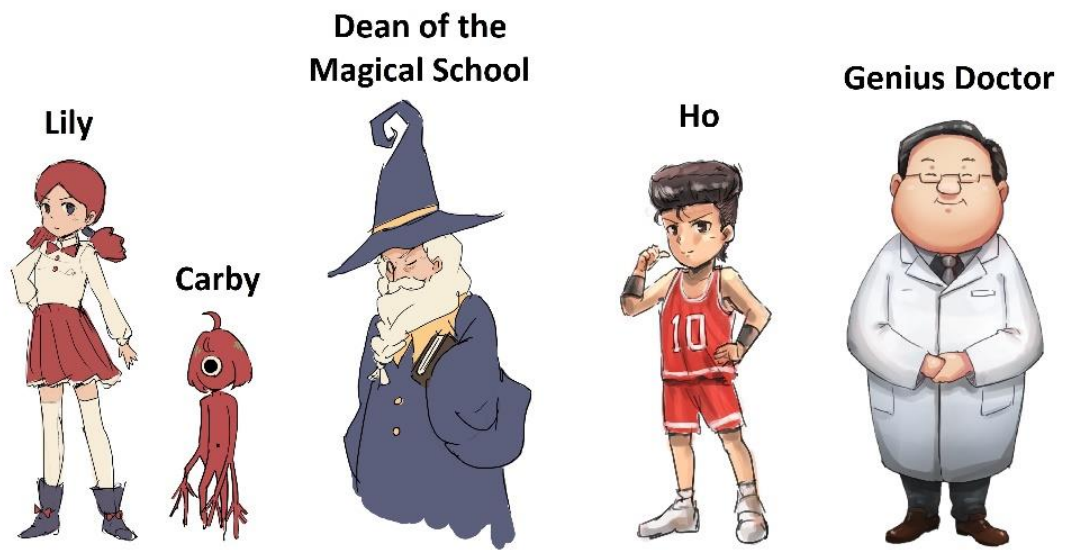

Figure 3: Characters' Appearance

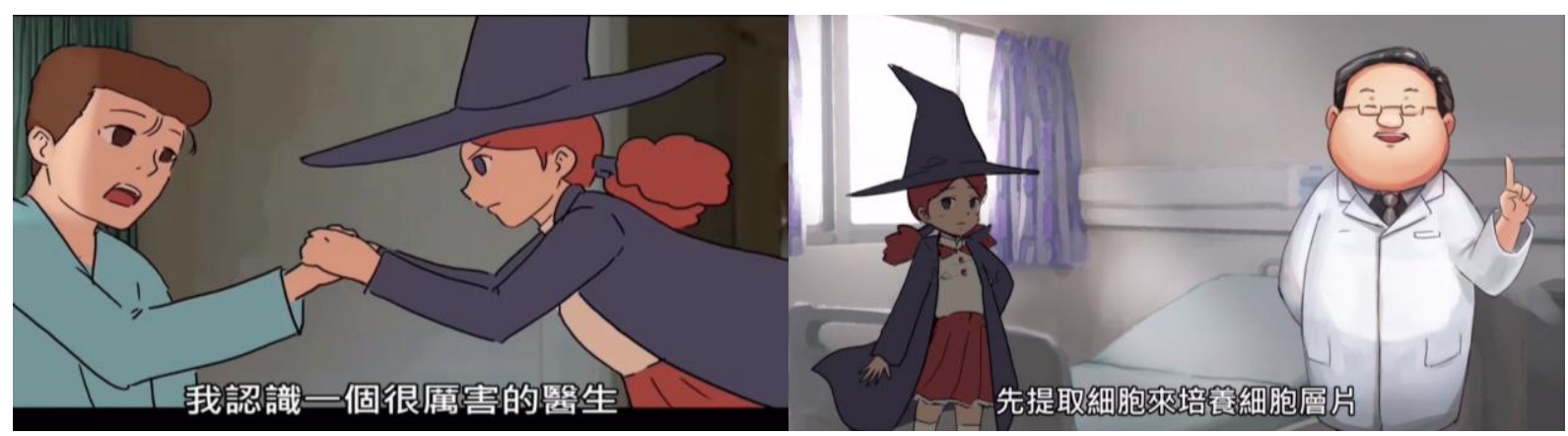

Figure 4: Screenshots in the Trailer Animation

\subsection{D Cell Sheets Animation}

The Ministry of Health and Welfare passed the "Regulations of Special Medical Techniques" on September 4, 2018, which approved the usage of Cell Therapy in Taiwan. This measure has greatly benefited those who needed cell therapy in Taiwan, and they no longer have to go to other countries for this kind of treatment. The types of cell therapy that have been approved currently include Peripheral Blood Stem Cell Transplantation, Immunocyte Therapy, Adipose-Derived Stem Cell Transplantation, Fibroblast Transplantation, Mesenchymal Stem Cell Transplantation, Chondrocyte Transplantation, etc. The last one is the application of Cell Sheets in Regenerative Medicine, which is also the topic our team has chosen for this research. 
The 2D animation is mainly about the process of nurturing cell sheets and how the surgery takes place. It also introduced the affiliated hospital of I-Shou University, E-Da Hospital, as the first hospital to approve cell sheets to be used in damaged knee joint cartilage transplantation. With the help of the Dean of E-Da Hospital, Professor Yuan-Kun Du, also known as one of the best surgeons in knee joint surgery, along with the cell sheets technology introduced from Japan, patients in Taiwan can be greatly benefited and treated properly.

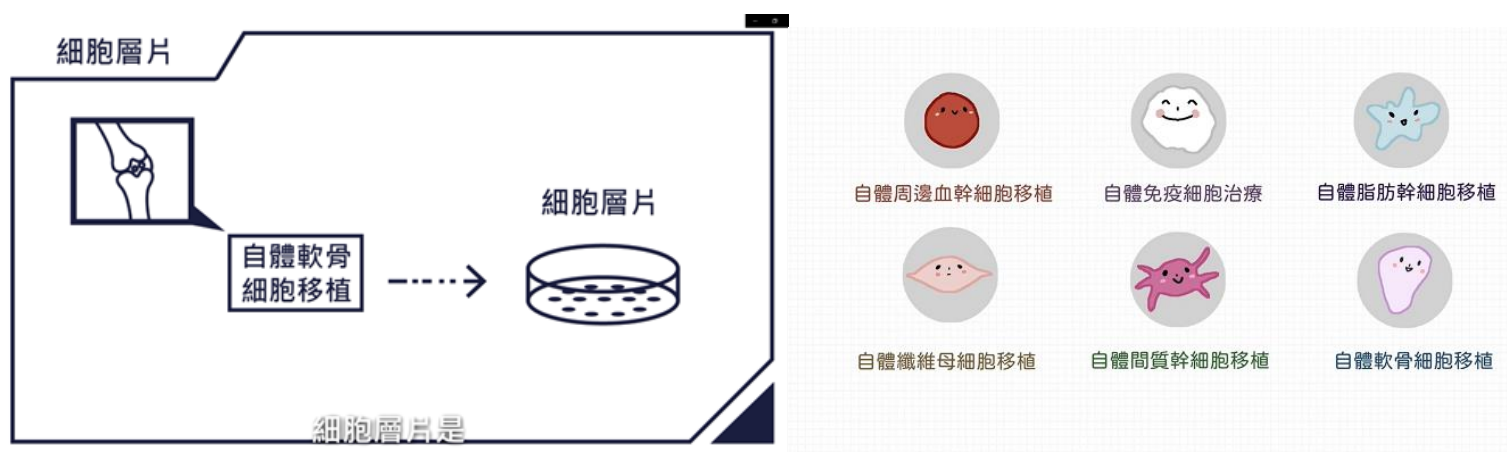

Figure 5: Screenshots from Cell Sheets Animation

\subsection{D Animation Module}

The nurturing of cell sheets is mainly originated from DNA replication and cell division. The process is often explained by images and videos, but this kind of way is not clear enough for the public to understand thoroughly. Therefore, we created a 3D animation mode and the public can use Merge Cube to view cell division from different angles. The 3D animation model is shown below:

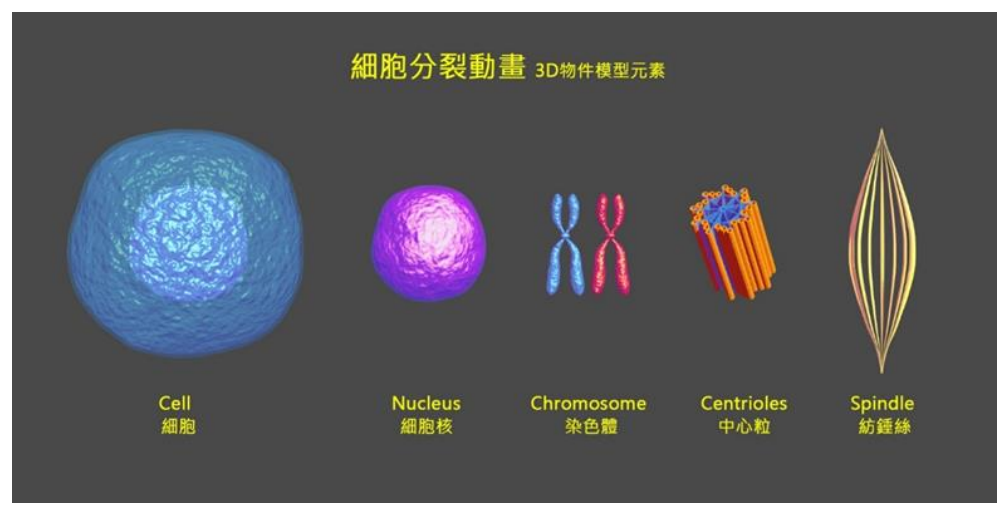

Figure 6: The 3D Animation Model of Cell Division

\subsection{AR Interaction Display}

The AR interaction display platform is built with Vuforia technology, Unity gaming engine development environment, and written with C\# to help disseminate cell sheets knowledge. If the public wants to experience the AR platform, all they need is to download the app and then put their smartphone in front of the Merge Cube. The screenshot of the AR interaction display platform is shown below:

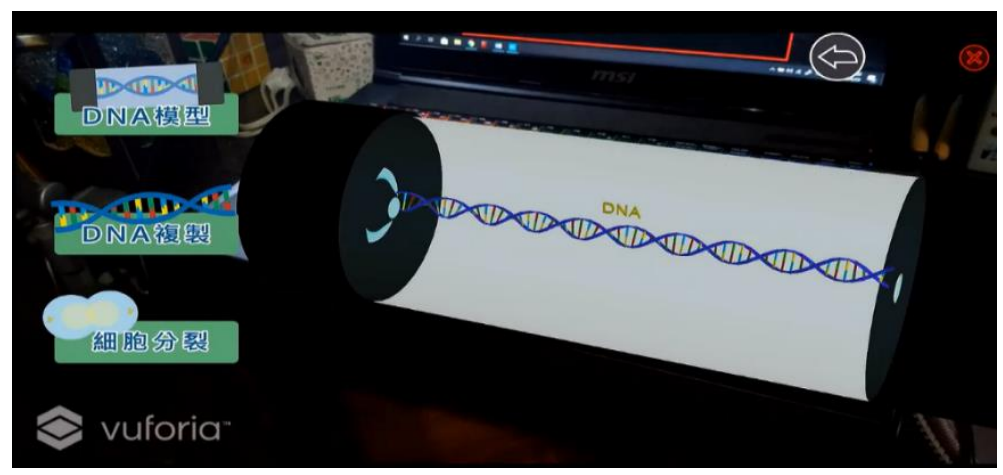

Figure 7: Screenshot of the AR Interactive Platform 


\subsection{VR Experience Environment}

Once users enter the VR scene, they will have to get familiar with the VR head-mounted device and the controllers, so they can easily learn about cell sheets knowledge while passing the VR games. In the VR game, the first level is nurturing cell sheets in the laboratory. Users have to collect the right amount of cell sheets in a limited time to pass this level. If they failed, they will have to go to the artificial joint level. With the experience of different levels in the game, users can understand how difficult and inconvenient it is to replace an artificial joint and how the cell sheets can greatly benefit the patients by making their organs grow naturally. The screenshot of the VR experience environment is shown below:

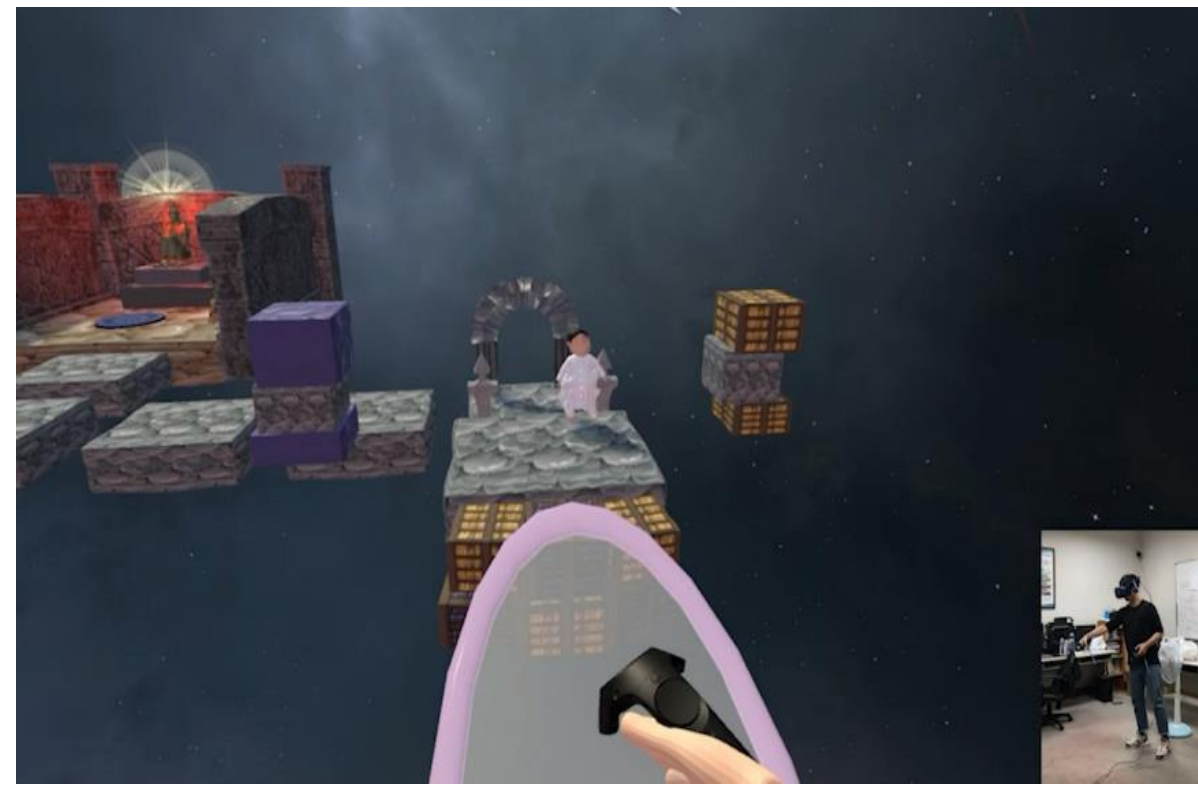

Figure 8: The Screenshot of the VR Experience Environment

\subsection{Exhibition}

The project results are displayed by a video explaining how reality technology is used in cell sheets knowledge dissemination (Lin, 2020), along with AR and VR experience events. We held an exhibition tour with the Ministry of Science and Technology in Kaohsiung National Science and Technology Museum, Hengchun Junior High School in Pingtung, and National Experimental High School At Central Taiwan Science Park in Taichung. Exhibition photos are shown below:

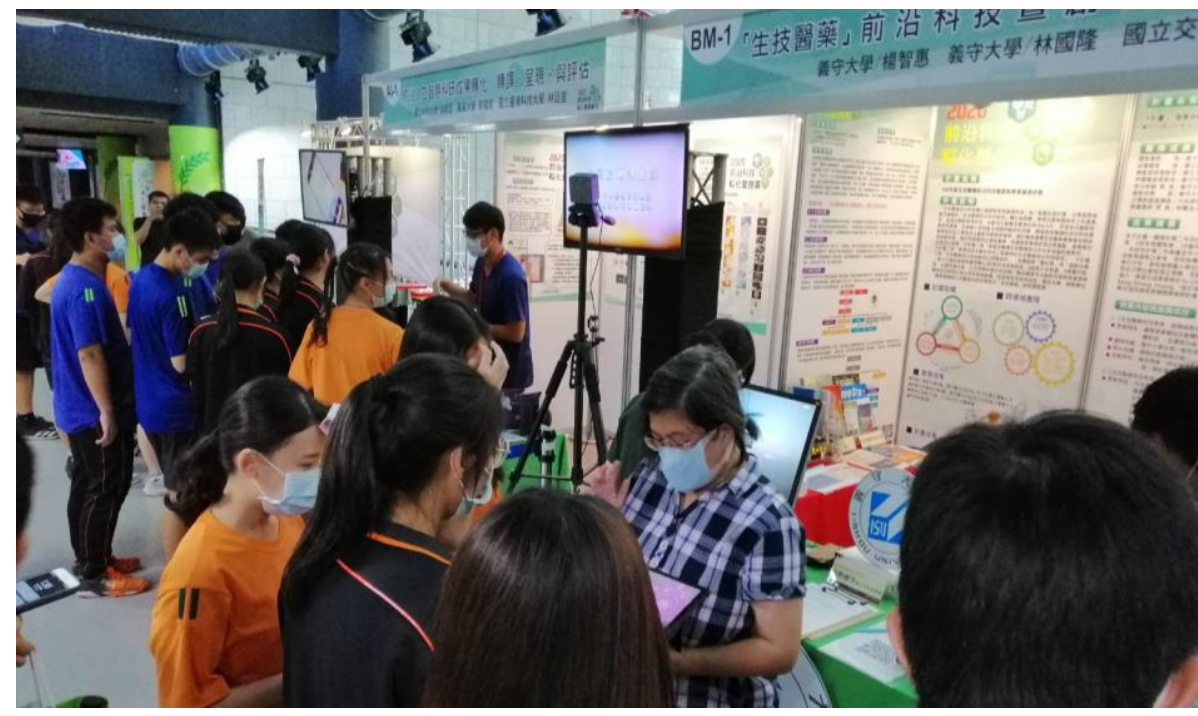

Figure 9: Exhibition tour at National Science and Technology Museum 


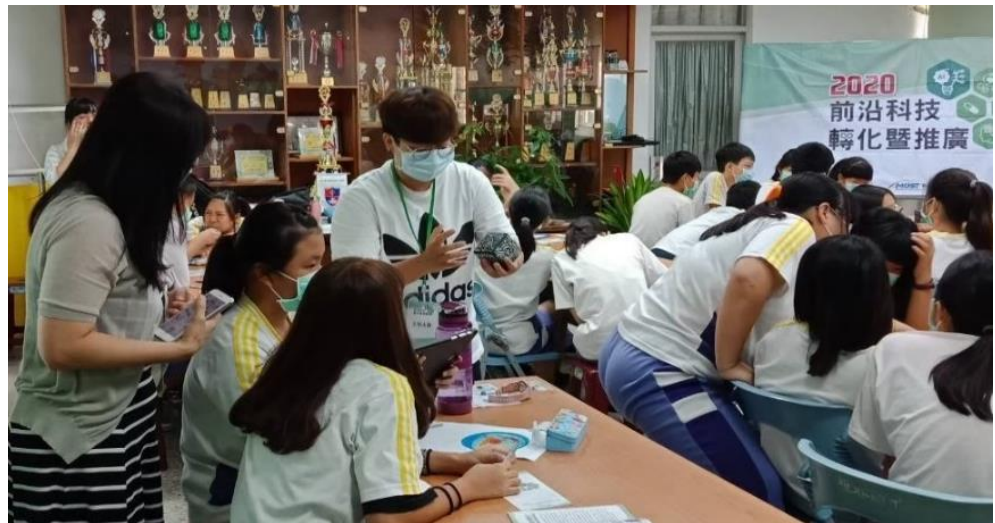

Figure 10: Exhibition tour at Hengchun Junior High School

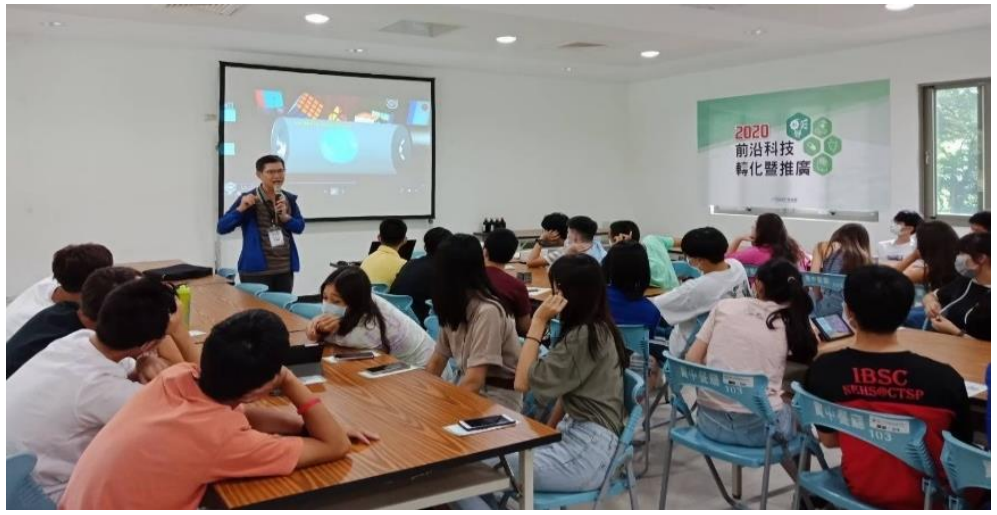

Figure 11: Exhibition tour at National Experimental High School At Central Taiwan Science Park in Taichung

\section{Conclusion}

To implement the combination of Biomedical courses and innovative education technology, we transformed the Biomedical courses by adding some elements of the digital creative industries. With the assistance of AR and VR technology in disseminating biomedical knowledge, we can provide the public state-of-the-art knowledge in technology and construct an innovative field full of diversity, entertainment, and education meaning. This paper is not only an extension of last year's AR research but also a creative project including VR technology to make the whole display more intriguing. We unveiled this year's research topic, Cell Sheets, to the public by making a trailer animation with the storyline of Ho getting into a car accident, being hospitalized, and receiving the help of Genius Doctor. Then we used 2D animation to introduce the Regulations of Special Medical Techniques, the principles of Cell Sheets in Regenerative Medicine, and the passion of Genius Doctor. Up next, we produced a 3D animation to explain the core concepts of cell sheets, cell replication, and cell division to help the public digest heavy medical knowledge more easily.

Finally, we used AR interactive display and VR experience environment to make an impression on the public. The AR interactive display includes a trailer, 2D animation, 3D animation to help the public learn about Glycoscience knowledge, and then they can put their smartphones in front of a cube-like object called Merge Cube to operate and interact with the animation. The VR experience environment uses VR to draw the public's attention to learn about Cell Sheets while going through different levels in the VR game. This project integrates Reality Technology and Digital Tools to help the public obtain knowledge about cell sheets in the Biomedical area. This whole new attempt and teaching material are expected to send the public on an extraordinary journey of learning new knowledge.

Funding: The project was supported by the Ministry of Science and Technology of Taiwan, grant no. MOST 108-2514-S-214-004. Acknowledgments: Special thanks to Professor Chih-Hui Yang from the Department of Biological Science \& Technology, College of Medicine from I-Shou University and Professor Sheng-Chang Chen from the Institute of Education from National Chiao Tung University for their support. The author would also like to thank Zih-Han Tang, Ming-Syuan Guo, Wun-Siou Tu, PeiYu Chen, Pei-Ling Li, Sin-Syuan Chen, Jia-Sing Fang, Pei-Yao Lin, Ruei-Rong Lin, Wei-Cheng Li, Man-Liou Tsuei, Wei-Hong Yang, Yan-Xuan Liu from the Department of Digital Media Design for their assistance.

Conflicts of Interest: The authors declare no conflict of interest. 


\section{References}

[1] Alaker, M., Wynn, G. R., Arulampalam, T. (2016). Virtual reality training in laparoscopic surgery: a systematic review \& meta-analysis. Int J Surg, 29, 85-94.

[2] Ardito, C., Buono, P., Costabile, M., Lanzilotti, R., \& Pederson, T. (2007). Re-experiencing History in Archaeological Parks by Playing a Mobile Augmented Reality Game. Lecture Notes in Computer Science, 4805, 357-366.

[3] Azuma, R. T. (1997). A Survey of Augmented Reality. Teleoperators and Virtual Environments, 6, 4, 355-385.

[4] Baldominos, A., Saez, Y., del Pozo, C.G. (2015). An approach to physical rehabilitation using state-of-the-art virtual reality and motion tracking technologies. Procedia Computer Science, 64, 10-16.

[5] Feiner, S. K. (2002). Augmented reality: A new way of seeing. Scientific American, 286, 4, 48-55.

[6] Formosa TV. (2017). Revolution of Japanese regenerative medicine. https://www.youtube.com/watch?v=dEYYQZhmzFc

[7] Gerber S. (2013). 13 industries that tech founders should watch. The Next Web. http://thenextweb.com/entrepreneur/2013/10/20/13industries-tech-founders-should-watch/

[8] Ha, H. G., \& Hong, J. (2016). Augmented Reality in Medicine. Hanyang Med Rev, 36, 242-247.

[9] Hackett, M., \& Proctor, M. (2016). Three-dimensional display technologies for anatomical education: a literature re-view. Journal of Science Education and Technology, 25, 4, 641-654.

[10] Li, A., Montano, Z., Chen, V. J., Gold, J. I. (2011). Virtual reality and pain management: current trends and future directions. Pain Manag, 1, 147-157.

[11] Li, L., Yu, F., Shi, D., Shi, J., Tian, Z., Yang, J., Wang, X., Jiang, Q. (2017). Review Article: Application of virtual reality technology in clinical medicine. Am J Transl Res, 9, 3867-3880.

[12] Liarokapis, F., \& de Freitas, S. (2010). A case study of augmented reality serious games. In M. Ebner, \& M. Schiefner (Eds.), Looking Toward the Future of Technology-Enhanced Education: Ubiquitous Learning and the Digital Native (pp. 178-191).

[13] Lin, G. L. (2020). Advocacy of Cell Sheet Using Reality Technology. https://youtu.be/AalgRcenuPo

[14] Malloy, K. M., Milling, L. S. (2010). The effectiveness of virtual reality distraction for pain reduction: a systematic review. Clin Psychol Rev, 30, 1011-1018.

[15] Mendenhall, S., Ha, V., Xu, Y., Tillery, P., Cohen, J., Sharp, J., Maclntyre, B. (2012). NerdHerder: Designing for Physical Actions in an Augmented Reality Puzzle Game. Proceedings of the International Conference on the Foundations of Digital Games (pp. 250-253).

[16] Palladino, T. (2018). GDC Survey Says Developers Are Bullish on HoloLens, Slow to Mobile AR Versus VR. https://next.reality.news/news/gdcsurvey-says-developers-are-bullish-hololens-slow-mobile-ar-versus-vr-0182397/

[17] Wang, L., Wang, X., Ju, Q., Li, Q., Li, M., \& Zhang, W. (2011). Game-Based Mobile Learning System for Campus on An-droid Platform. Proceedings of the 6th international conference on E-learning and games, edutainment technologies (pp. 55-62). 